\title{
Hiperplasia eritroblástica secundaria a infección aguda por parvovirus B19
}

\author{
Erythroblastic hyperplasia secondary to acute parvovirus B19 infection: A case report
}

Natalia Gómez', Strella de la Hayes² y Gabriela Rozas³

'Departamento de Anatomía Patológica. Hospital Barros Luco Trudeau. Santiago, Chile.
Departamento de Hematología. Hospital Barros Luco Trudeau. Santiago, Chile.
${ }^{3}$ Departamento de Anatomía patológica. Hospital Dr. Eduardo Pereira. Valparaíso, Chile.

Ninguno de los autores declara tener conflictos de interés.

No hubo aporte de fuentes de financiamiento.

Recibido: 18 de mayo de 2020 / Aceptado: 28 de octubre de 2020

\section{Resumen}

La infección aguda por parvovirus B19 es una enfermedad autolimitada en pacientes sin trastornos inmunitarios. Sin embargo, en pacientes con discrasias sanguíneas pueden manifestarse con una crisis aplásica. Presentamos el caso de un varón de 48 años, con una esferocitosis hereditaria no diagnosticada previamente, la cual debutó con una crisis aplásica inducida por una infección aguda de parvovirus B19. La sospecha clínica se planteó luego del análisis histopatológico de la médula ósea, en el que se observó una hiperplasia eritroblástica, con precursores eritroides gigantes e inclusiones nucleares virales, y cuyo análisis inmunohistoquímico fue positivo para la proteína de la cápside viral VP1 y VP2 de parvovirus B19 en células infectadas. Se confirmó la sospecha diagnóstica con la detección de anticuerpos IgM de parvovirus B19. De acuerdo a nuestra revisión, este es el primer reporte de un adulto en Latinoamérica que debutó con una crisis aplásica inducida por una infección aguda por parvovirus B19, como primera manifestación de una esferocitosis hereditaria.

Palabras claves: esferocitosis hereditaria; parvovirus B19; crisis aplásica.

\section{Introducción}

$\mathrm{L}$ a infección por parvovirus B19 es muy frecuente, con una seroconversión que varía entre 5 y $10 \%$ en niños, y hasta $60 \%$ en adultos de 30 años $^{1,2}$. Es un virus con cadena simple de ADN y tropismo por las células eritroides progenitoras, donde ocurre su replicación ${ }^{3}$.

Su manifestación clínica es variable, con un espectro de síntomas que van desde una infección subclínica, a cuadros febriles tales como

\section{Abstract}

Acute parvovirus B19 infection is a self-limiting disease in patients with normal immune response. However, in patients with blood dyscrasias, it is possible to present with an aplastic crisis. We present the case of a 48-year-old man who had developed an aplastic crisis as a result of an acute parvovirus B19 infection with an undiagnosed hereditary spherocytosis. Suspicions of the parvovirus infection began to arise after a routine bone marrow histopathological analysis which showed erythroblastic hyperplasia with giant erythroid precursor and viral inclusions. A subsequent immunohistochemical analysis tested positive for VP1 and VP2 capsid proteins of parvovirus B19 in infected cells. The diagnostic suspicion was later confirmed with the presence of anti-parvovirus B19 IgM. According to our review, this is the first published case in Latin America that documents an adult patient with normal immune response whose first symptom of hereditary spherocytosis was an aplastic crisis induced by an acute parvovirus B19 infection.

Keywords: hereditary spherocytosis; human parvovirus B19; aplastic crisis.

el eritema infeccioso y síndrome de poli-artropatía hasta la crisis aplásica, esta última descrita en pacientes con hemoglobinopatías o anemias hemolíticas ${ }^{1,4}$.

Aunque se han descrito casos de crisis aplásica por parvovirus B19 en pacientes con esferocitosis hereditaria, particularmente en pacientes pediátricos, existen muy pocos reportes en adultos, siendo escasas las publicaciones que muestran sus características morfológicas en la médula ósea ${ }^{5}$. 


\section{—}

Presentamos el caso de un adulto sin antecedentes clínicos de inmunodeficiencia, que debutó con una crisis aplásica, secundaria a una infección aguda por parvovirus B19, sospechado por los hallazgos histopatológicos en la médula ósea, y confirmado por la detección de proteínas de la cápside viral con técnica inmunohistoquímica y mediante la detección de IgM contra parvovirus B19, y en cuyo estudio dirigido se detectó una esferocitosis hereditaria.

\section{Caso clínico}

Varón de 48 años sin antecedentes mórbidos conocidos, consultó por un día de evolución de compromiso del estado general y fiebre cuantificada hasta $39^{\circ} \mathrm{C}$ e ictericia indirecta. A la entrevista clínica dirigida, no informó lesiones cutáneas, síntomas respiratorios, artralgias ni otros síntomas. Al examen físico no se encontró exantema, esplenomegalia y/o hepatomegalia. Los exámenes de laboratorio inicial mostraron una anemia grave con hemoglobina de 9,8 g/dl; hematocrito de 26,1\%; 5.360 leucocitos $/ \mathrm{mm}^{3} ; 139.000$ plaquetas $/ \mathrm{mm}^{3}$ y reticulocitos de $0,4 \%$, con elevación de LDH hasta $652 \mathrm{U} / 1$. El frotis sanguíneo mostró esferocitos. Evolucionó con 3.190 leucocitos $/ \mathrm{mm}^{3}$ y una caída de la hemoglobina hasta 4,7 $\mathrm{gr} / \mathrm{dl}$ que requirió una transfusión de glóbulos rojos.

Las serologías para VHB, VHC, VIH, así como el test de Coombs directo fueron negativos. Los niveles de folato y vitamina B12 se encontraban dentro de rango normal, al igual que el estudio de citogenética. En la citometría de flujo no se observaron blastos en la médula ósea y se excluyó una hemoglobinuria paroxística nocturna (evaluado con inmunofenotipo de proteína vinculada a GPI).

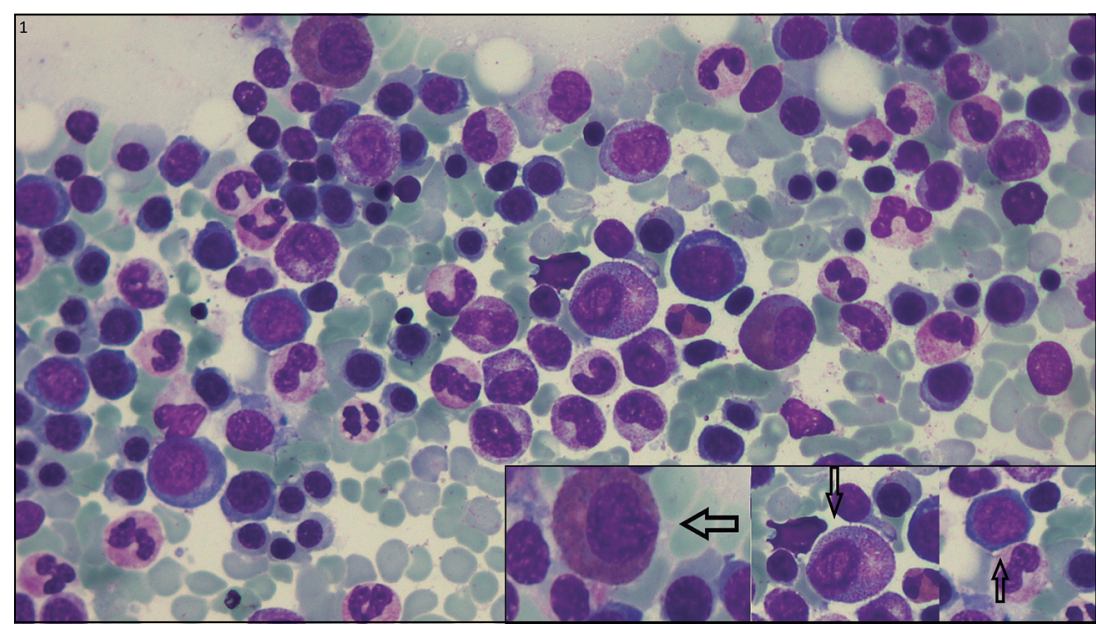

Figura 1. Aspirado de médula ósea. Eritroblastos inmaduros gigantes (pronormoblastos), con inclusiones nucleares (flechas). Tinción de Wright-Giemsa, 40x.
La prueba de fragilidad osmótica usando el método de Dacie fue positivo.

Se realizó un estudio imagenológico que mostró una esplenomegalia de hasta $18 \mathrm{~cm}$. En el mielograma se observó una hiperplasia eritroide con proeritroblastos gigantes con algunas inclusiones nucleares moradas (Figura 1).

Se completó el estudio con una biopsia percutánea de médula ósea con trefina. El material obtenido fue fijado en formalina al $10 \%$, descalcificado con EDTA por $48 \mathrm{~h}$, e incluido en parafina. Se realizaron cortes de 4 micrones de grosor y se les realizó una tinción de hematoxilinaeosina (H-E). Adicionalmente, se realizó un estudio inmunohistoquímico con anticuerpos monoclonales primarios contra CD71 (clon MRQ-48), mediante método de tinción automatizado (Autostainer Link 48, Envision Flex High PH, Dako, Denmark) y contra la proteína de la cápside viral VP1 y VP2, de parvovirus B19 (clon R92F6), mediante el método de tinción automatizada (método de detección Ultraview ${ }^{\circledR}$, Ventana System). La técnica de inmunohistoquímica permite identificar tejidos y componentes celulares (antígenos), mediante una reacción antígeno-anticuerpo. Para ello se realizó la incubación del tejido con el respectivo anticuerpo, en donde una reacción positiva significa unión del antígeno con el anticuerpo. Esta reacción positiva se puede observar gracias a un procedimiento llamado "revelación", en donde se aplica un cromógeno que genera una reacción visible la que puede ser café o rojo ${ }^{6}$.

El receptor de transferrina CD71 o "cluster of differentiation 71 " es una proteína integral de transmembrana que media la incorporación celular de complejos transferina-hierro y se encuentra altamente expresado en células eritroides precursoras ${ }^{7}$. Su expresión es mayor en los precursores eritroides tempranos hasta en fases intermedias de los normoblastos y disminuye en la fase reticulocítica, para finalmente perder su expresión en los eritrocitos maduros ${ }^{7}$. En nuestro caso la biopsia de médula ósea mostró una celularidad aumentada para la edad del paciente, a expensas de una serie eritroide con cambios megaloblastoides e inclusiones nucleares. Se identificaron algunos pro-eritoblastos gigantes con efecto citopático viral, con marginación de la cromatina en la periferia e inclusiones virales (Figura 2, 3 y 4). El estudio inmunohistoquímico demostró que la serie eritroide y sus precursores fueron inmunorreactivos para CD71 (Figura 5). Las células infectadas fueron positivas con anticuerpos monoclonales contra proteínas de la cápside viral VP1 y VP2 del parvovirus B19 (Figura 6).

La expresión de CD71, en las células atípicas con cambios megaloblastoides, nos permite confirmar que la estirpe celular en donde las inclusiones y alteraciones citopáticas virales se encuentran, son precursores eritroi$\operatorname{des}^{7}$, destacando el tropismo de estas partículas virales por 

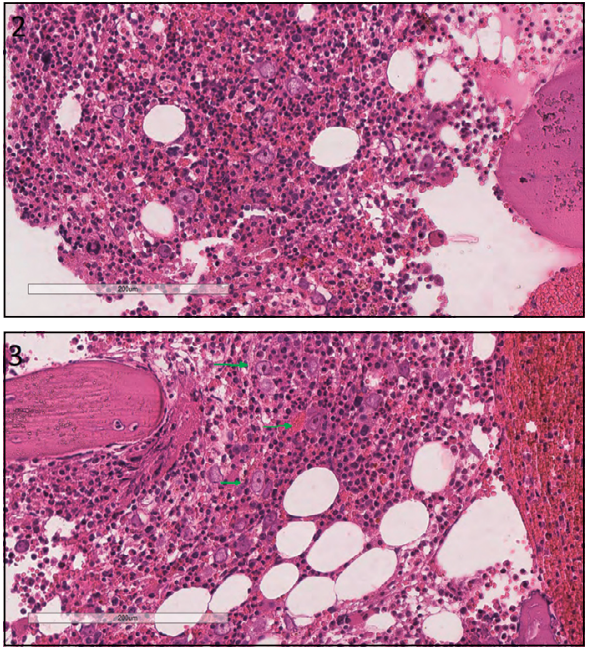

Figuras 2 y 3. Biopsia de médula ósea. Médula ósea hipercelular, con numerosos precursores eritroides aumentados de tamaño, y núcleo pleomorfo, cromatina laxa y marginada hacia la periferia. Se identifican inclusiones virales eosinófilas (flechas). Tinción Hematoxilina-Eosina, 20x.

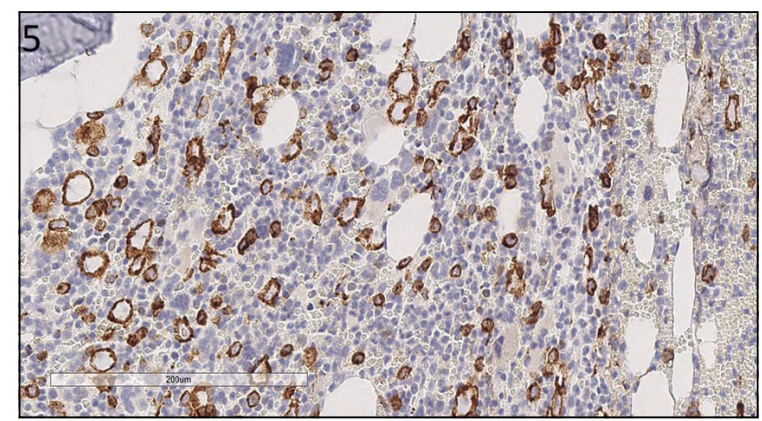

Figura 5. Biopsia de médula ósea. Tinción de inmunohistoquímica con anticuerpos contra CD71 positivo en células precursoras atípicas de estirpe eritroide (flechas). 20x.

esta estirpe celular. Así mismo, la expresión positiva de proteínas de la cápside viral VP1 y VP2 en inclusiones eosinófilas, confirma la presencia de partículas virales en dichas células.

El estudio serológico mostró detección de inmunoglobulinas IgM e IgG contra parvovirus B19, detectado mediante inmunofluorescencia indirecta en sangre (Biotrin Parvovirus B19 IgG, IgM).

El paciente evolucionó favorablemente con aumento progresivo de la hemoglobina, hematocrito, plaquetas y leucocitos, sin tratamiento adicional.

Se confirmó así el diagnóstico de una esferocitosis hereditaria, manifestada como una crisis aplásica inducida por una infección aguda de parvovirus B19, y diagnosticado por las alteraciones morfológicas de la médula ósea.

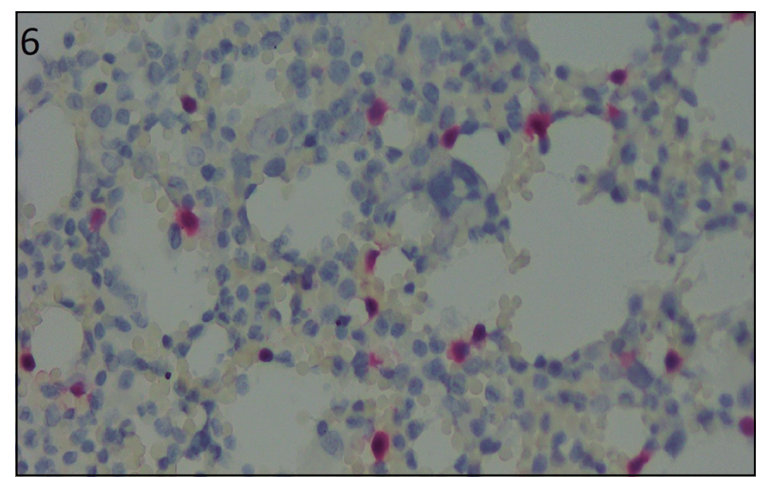

Figura 6. Biopsia de médula ósea. Análisis inmunohistoquímico con anticuerpos contra proteínas de la cápside viral VP1 y VP2 del parvovirus B19 en células infectadas (flechas). 40x.

\section{Discusión}

El parvovirus B19 es un virus con una cadena simple de ADN con tropismo eritroide, el que está dado por la distribución del receptor celular, el antígeno globósido P. El receptor es un glico-esfingolípido neutro encontrado predominantemente en los eritrocitos y sus precursores, conocido como antígeno sanguíneo del grupo $\mathrm{P}^{3,8}$. El ADN viral codifica para tres proteínas principales: VP1 y VP2, que se distribuyen en la cápside viral y NS1 que es una proteína no estructural ${ }^{3,8}$. Las dos primeras tienen una relevancia diagnóstica ya que pueden ser detectadas mediante la técnica de inmunohistoquímica y por inmunofluorescencia indirecta. La infección por este virus induce un arresto del ciclo celular en fase G1 y G2. Por 
otro lado, NS1 induce citotoxicidad activando la vía de las caspasas y sobrexpresando BCL-2, siendo NS1, por ende, una proteína que induce apoptosis en las células afectadas por el virus ${ }^{3}$.

Si bien la mayoría de las personas con infección por parvovirus B19 son asintomáticas o presentan síntomas leves e inespecíficos similar a un resfrío común, se han descritos varias condiciones asociadas a esta infección como, por ejemplo, eritema infeccioso, artropatías persistentes agudas o crónicas, y erupciones purpúricas en manos y pies (síndrome guante y calcetín). Por otro lado, en una proporción menor de pacientes, la infección aguda por parvovirus puede tener consecuencias graves y gatillar una crisis aplásica transitoria, aplasia de glóbulos rojos crónica, hidrops fetal, o anemia congénita ${ }^{4}$.

La crisis aplásica se ha descrito en el contexto de distintos desórdenes hemolíticos subyacentes, como es el caso de la esferocitosis hereditaria, las que acortan el promedio de vida de los glóbulos rojos a 5-15 días ${ }^{3,8}$. Esta crisis puede ser gatillada por distintos estímulos estresantes hacia los eritrocitos, como la infección aguda por parvovirus B19, que induce y acelera la muerte de células eritroides, resultando en una anemia grave o crisis aplásica $^{3}$, tal como en el caso presentado. Usualmente en un individuo sano, la infección aguda de este virus es compensada por la reserva hematopoyética dada por el ciclo de vida del glóbulo rojo normal (120 días), lo que evita que la falla en la eritropoyesis sea clínicamente aparente ${ }^{8}$. Sin embargo, en el contexto de un paciente ya sea inmunocomprometido o con algún desorden hematopoyético subyacente, la infección por parvovirus B19 puede manifestarse como una crisis aplásica ${ }^{8,9}$.

En pacientes con crisis aplásica los exámenes de laboratorio pueden mostrar bajos niveles de reticulocitos (0-1\%) y caída de los niveles de hemoglobina al menos en $2 \mathrm{~g} / \mathrm{dl}$ del basal del paciente ${ }^{10}$.

La infección aguda por parvovirus B19 se confirma con la detección en el suero de IgM específicas, lo que traduce que la infección ocurrió dos a tres meses atrás aproximadamente ${ }^{1}$. La IgG sérica es detectable desde el segundo día de la infección aproximadamente, y se mantiene positivo durante toda la vida, por lo tanto la presencia de IgG no necesariamente indica infección aguda $^{1}$. En pacientes inmunocomprometidos, los niveles séricos de $\operatorname{IgG}$ e $\operatorname{IgM}$ no son confiables, por lo tanto, el mejor método diagnóstico en estos casos es la demostración de altos títulos de ADN viral, detectado mediante RPC ${ }^{1}$.
Si bien los cambios morfológicos en la médula ósea están bien descritos, no es frecuente observarlos, pues en general no se realiza su estudio, ya que el diagnóstico puede establecerse con métodos no invasores, como la detección de IgM. El estudio de médula ósea se debe realizar siempre y cuando haya sospecha clínica de síndrome mielodisplásico o leucemia. En este caso, el enfoque está condicionado a excluir dichos síndromes.

La ausencia de elementos eritroides maduros asociado a la presencia de pro-normoblastos gigantes ${ }^{11,12}$, con inclusiones virales nucleares y marginación de la cromatina en el estudio histológico de la médula ósea, son claves para el diagnóstico de una infección aguda por parvovirus B19. Por lo demás, esto puede ser reafirmado mediante la detección de proteínas de la cápside viral, a través de una técnica de inmunohistoquímica. Hay que considerar que los cambios morfológicos descritos, pueden ser fácilmente mal interpretados como una displasia de la serie eritroide, conduciendo al diagnóstico erróneo de un síndrome mielodisplásico ${ }^{13,14}$.

El tratamiento de la crisis aplásica secundaria a una infección aguda por parvovirus B19 consiste en la transfusión de glóbulos rojos y el eventual uso de inmunoglobulinas en pacientes inmunocomprometidos ${ }^{1,8,9}$.

En la literatura especializada encontramos diecisiete reportes de casos donde el diagnóstico fue efectuado por la alta sospecha de los hallazgos encontrados en la biopsia de médula ósea. En doce de ellos, los pacientes se presentaron en un contexto de inmunosupresión, dos se asociaron a discrasias sanguíneas (anemia falciforme), uno correspondió a una mujer embarazada, otro fue un paciente pediátrico inmunocompetente y en el resto de los casos no se informaron antecedentes conocidos ${ }^{9,14-22}$. Según nuestra revisión, esta es la primera publicación en Latinoamérica que reporta un paciente adulto, sin trastornos en el desarrollo de la respuesta inmune, cuyo primer síntoma de la esferocitosis hereditaria fue una crisis aplásica, inducida por infección aguda de parvovirus B19, diagnosticado por los cambios morfológicos encontrados en la biopsia de médula ósea.

Es importante reconocer las manifestaciones clínicas y los hallazgos histopatológicos con que la infección aguda de este virus se manifiesta, puesto que son fácilmente pasados por alto, o mal interpretadas, lo que podría retardar el diagnóstico y su posterior tratamiento.

Agradecimientos: Sebastián Ormeño y Abraham Folmsbee por su apoyo y ayuda. 


\section{Referencias bibliográficas}

1.- Kimberlin D W, Brady M T, Jackson M A. American Academy of Pediatrics Committee on Infectious Diseases. 31 st ed. Red Book 20182021. Report of the Committee on Infectious Diseases. Red Book Report of the Committee on Infectious Diseases. 2018. 602-606 p. Itasca, IL: American Academy of Pediatrics; 2018.

2.- Bennett J E, Dolin R, Blaser M. Mandell D and B. Principles and Practice of Infectious Diseases, Ninth edition. 2020. 1968-1974 p. Elsevier, Philadelphia

3.- Chisaka H, Morita E, Yaegashi N, Sugamura K. Parvovirus B19 and the pathogenesis of anaemia. Rev Med Virol 2003; 13: 347-59.

4.- Servey JT, Reamy B V, Hodge J. Clinical presentations of parvovirus B19 infection. Am Fam Physician 2007; 75(3): 373-6.

5.- Kobayashi Y, Hatta Y, Ishiwatari Y, Kanno H, Takei M. Human parvovirus B19-induced aplastic crisis in an adult patient with hereditary spherocytosis: a case report and review of the literature. BMC Res Notes 2014; 7: 137. doi: 10.1186/1756-0500-7-137.

6.- Kabiraj A, Gupta J, Khaitan T, Bhattacharya PT. Principle and techniques of immunohistochemistry - a review. Int J Biol Med Res 2015; 6: 5204-10.

7.- $\quad$ Marsee D K, Pinkus G S, Yu H. CD71 (transferrin receptor): An effective marker for erythroid precursors in bone marrow biopsy specimens. Am J Clin Pathol 2010; 134: 42935. doi: 10.1309/AJCPCRK3MOAOJ6AT.
8.- Brown KE, Young NS. Parvoviruses and bone marrow failure. Stem Cells 1996; 14: 151-63. doi: 10.1002/stem.140151.

9.- Manthri S, Chakraborty K. Acute parvovirus B19 infection diagnosed by bone marrow biopsy. BMJ Case Rep 2019; 12: e230403. doi:10.1136/bcr-2019- 230403.

10.- Heegaard E D, Brown K E. Human Parvovirus B19. Clin Microbiol Rev 2002; 15: 485-505. doi: 10.1128/CMR.15.3.485505.2002 .

11.- Brown KE. Haematological consequences of parvovirus B19 infection. Bailliere's Best Pract Res Clin Haematol 2000; 13: 245-59. doi: 10.1053/beha.1999.0071.

12.- Young N S, Brown K E. Parvovirus B19. N Engl J Med 2004; 350: 586-97. doi: 10.1056/ NEJMra030840.

13.- Baurmann H, Schwarz T F, Oertel J, Roggenderf M, Huhn D. Acute parvovirus B 19 infection mimicking myelodysplastic syndrome of the bone marrow. Ann Hematol 1992; 64: 43-5. doi: 10.1007/BF01811471.

14.- Rinn R, Chow W S, Pinkerton P H. Transient acquired myelodysplasia associated with parvovirus B19 infection in a patient with congenital spherocytosis. Am J Hematol 1995; 50: 71-2. doi: 10.1002/ajh.2830500126.

15.- Chen S, Howard O. Parvovirus B19 Infection. N Engl J Med 2004; 350: 598. doi: 10.1056/ NEJMicm010759.

16.- Gupta D, Wu S L, Nguyen AND. Human Parvovirus B19 in the bone marrow with negative viral serologic results. Lab Med 2001;
32: 429-31. doi: 10.1309/X8F6-RPYT-XH1LGYY0.

17.- Rogers H J, Feasel P. Acute parvovirus B19 infection detected in bone marrow biopsy. Blood 2015; 126: 1630. doi: 10.1182 blood-2015-07-656157.

18.- Crook T W, Rogers B B, McFarland R D, Kroft S H, Muretto P, Hernandez J A, et al. Unusual bone marrow manifestations of parvovirus B19 infection in immunocompromised patients. Hum Pathol 2000; 31: 161-8. doi: 10.1016/s0046$8177(00) 80215-4$

19.- Ganzel C, Constantin R. Parvovirus B19 diagnosed by bone marrow biopsy. Blood 2015; 125: 3351. doi: 10.1182/ blood-2015-02-628008.

20.- Gadage V, Viswanathan S, Kunal S, Subramanian P, Gujral S. Parvovirus B19 presenting with persistent pancytopenia in a patient of T-ALL post induction chemotherapy diagnosed on bone marrow examination. Indian J Pathol Microbiol 2011; 54: 603-5. doi: 10.4103/0377-4929.85109.

21.- Borkowski J, Amrikach M, Hudnal D. Fulminant parvovirus infection following erythropoietin treatment in a patient with acquired immunodeficiency Syndrome. Arch Pathol Lab Med 2000; 124: 441-5.

22.- Agrawal M, Paul R T, Pamu P, Avmr N. Parvovirus B19 induced transient aplastic crisis in an immunocompetent child. Turk Patoloji Derg 2015; 31: 158-60. doi: 10.5146/ tjpath.2014.01263. 